\title{
USOS EXPLORATÓRIOS E SUSTENTÁVEIS DA NATUREZA NO ENTORNO DO PARQUE NACIONAL DA SERRA DO ITAJAÍ EM INDAIAL-SC
}

\section{EXPLORATORY AND SUSTAINABLE USES OF NATURE AROUND THE SERRA DO ITAJAÍ NATIONAL PARK IN INDAIAL-SC}

\author{
EXPLORACIÓN Y UTILIZACIÓN SOSTENIBLE DE LA NATURALEZA \\ ALREDEDOR DEL PARQUE NACIONAL SERRA DO ITAJAÍ EN INDAIAL-SC
}

\author{
Gilberto Friedenreich dos Santos ${ }^{1}$ \\ Martin Stabel Garrote ${ }^{2}$
}

\begin{abstract}
RESUMO
O estudo trata das relações sociedade e natureza para compreender os usos exploratórios e sustentáveis da natureza das comunidades localizadas na zona de amortecimento (ZA) e entorno do Parque Nacional da Serra do Itajaí (PNSI), especificamente no município de Indaial, Vale do Itajaí (SC). O objetivo da pesquisa é investigar a história dos usos dos recursos naturais da natureza antes e após a criação do PNSI em 2004. Trata-se de uma pesquisa exploratória de caráter histórico baseada em fontes bibliográficas, especialmente regionais, e o acervo de transcrições e áudios de entrevistas do grupo de pesquisa. A identificação de iniciativas de usos sustentáveis nas comunidades consistiu na aplicação de questionários com proprietários de empreendimentos. A atividade de campo inclui a observação da paisagem para identificar o processo de ocupação e uso dos recursos naturais. Até a década de 1980 o desenvolvimento das comunidades associava-se basicamente à agricultura e exploração madeireira. A partir de 1990, leis ambientais proíbem a exploração da Mata Atlântica e rompem um período de intensa exploração. A criação do PNSI consolida o processo de proteção da biodiversidade e dos recursos hídricos na região, que favorece a conservação dos atrativos naturais e propiciam o desenvolvimento de empreendimentos e atividades de lazer.
\end{abstract}

Palavras-chave: Parque Nacional da Serra do Itajaí. Comunidades de entorno. Indaial. Uso exploratório. Desenvolvimento Sustentável.

\footnotetext{
${ }^{1}$ Doutor em Geografia, professor do Programa de Pós-graduação em Desenvolvimento Regional, Centro de Ciências Humanas e da Comunicação, Universidade Regional de Blumenau, Blumenau. Santa Catarina. Brasil. E-mail: frieden@furb.br. ORCID ID: https://orcid.org/0000-0001-6021-8966

${ }^{2}$ Mestre em Desenvolvimento Regional, pesquisador do Grupo de Pesquisa de História Ambiental do Vale do Itajaí, Universidade Regional de Blumenau. Blumenau. Santa Catarina. Brasil. E-mail: martin sg@,furb.br. ORCID ID: https://orcid.org/0000-0002-8034-3147
} 


\begin{abstract}
The study deals with the relationships between society and nature in order to understand the exploratory and sustainable uses of nature in the communities located in the buffer zone and surroundings of the Serra do Itajaí National Park (PNSI), more specifically in the municipality of Indaial. The objective of the research is to investigate the history of the uses of nature before and after the creation of the PNSI in 2004. It is an exploratory research with historical character using regional bibliography, and the collection of transcriptions and interviews made by the research group. The identification of sustainable use initiatives in the communities consisted in the application of questionnaires with local enterpreneurs. The field activity includes the observation of the landscape to identify the process of occupation and use of natural resources. Until the 1980s, community development was basically associated with agriculture and logging. Since 1990, environmental laws have prohibited the exploitation of the rainforest and have put an end to a long period of intense exploitation. The PNSI comes to consolidate for protection of biodiversity and water resources in the region, and this fact favors the conservation of the area and fosters the development of leisure activities in the park.
\end{abstract}

Keywords: Serra do Itajaí National Park. Around communities. Indaial. Exploratory use. Sustainable Development.

\title{
RESUMEN
}

El estudio aborda las relaciones entre sociedad y la naturaleza comprendiendo los usos de explotación y sostenibles de la naturaleza de las comunidades en la zona de amortiguamiento (ZA) y alrededor del Parque Nacional Serra do Itajaí (PNSI), en el municipio de Indaial, Vale do Itajaí (SC). El objetivo fue investigar la historia de los usos de los recursos naturales de la naturaleza antes y después de la creación del PNSI en 2004. Es una investigación exploratoria de carácter histórico basada en fuentes bibliográficas, especialmente regionales, y la colección de transcripciones y audios de las entrevistas del grupo de investigación. La identificación de iniciativas de uso sostenible en las comunidades consistió en la aplicación de cuestionarios con propietarios de empresas. La actividad de campo incluye la observación del paisaje para identificar el proceso de ocupación y uso de los recursos naturales. Hasta la década de 1980, el desarrollo comunitario estaba asociado básicamente con la agricultura y extracción de madera. A partir de 1990, las leyes ambientales prohíben la explotación del bosque atlántico y rompen un período de intensa explotación. La creación del PNSI consolida el proceso de protección de la biodiversidad y los recursos hídricos en la región, lo que favorece la conservación de los atractivos naturales y promueve el desarrollo de empresas y actividades de ocio.

Palabras-clave: Parque Nacional Serra do Itajaí. Comunidades circundantes. Indaial. Usos de explotación. exploratório. Desarrollo Sostenible.

Como citar este artigo: SANTOS, Gilberto Friedenreich dos; GARROTE, Martin Stabel. Usos exploratórios e sustentáveis da natureza no entorno do Parque Nacional da Serra do Itajaí em Indaial-SC. DRd - Desenvolvimento Regional em debate, v. 10, p. 283-301, 28/04/2020. DOI: https://doi.org/10.24302/drd.v10i0.2563 
Artigo recebido em: 05/12/2019

Artigo aprovado em: 28/04/2020

Artigo publicado em: 28/04/2020

\section{INTRODUÇÃO}

O estudo está voltado para a temática das relações sociedade e natureza para compreender os usos exploratórios e sustentáveis dos recursos naturais em um território que foi palco de diferentes modelos de desenvolvimento. O objetivo da pesquisa foi investigar a história dos usos dos recursos naturais da natureza antes e após a criação do Parque Nacional da Serra do Itajaí no município de Indaial. O período de estudo corresponde ao início da colonização na segunda metade do século XIX até a criação do parque em 2004, e posterior a sua criação. Essa divisão temporal representa a identificação de períodos distintos no uso dos recursos naturais e do desenvolvimento regional.

O PNSI é uma Unidade de Conservação (UC) de Proteção Integral criada em 4 de junho de 2004, com 57.374 hectares, abrangendo 9 municípios: Indaial, Blumenau, Botuverá, Gaspar, Vidal Ramos, Apiúna, Guabiruba, Ascurra e Presidente Nereu. O PNSI abrange grande parte da Serra do Itajaí e "representa $0,6 \%$ da área total do estado de Santa Catarina e 2,5\% da área remanescente de Mata Atlântica no estado." (BRASIL, 2009, p. 20). Constitui a maior área protegida de toda a Bacia Hidrográfica do Rio Itajaí. O interesse específico no município de Indaial deve-se ao fato de sua área de $431 \mathrm{~km}^{2}$ apresentar o maior índice de abrangência do PNSI com quase $1 / 3$ do território (32,30\%) (BRASIL, 2009). Nos demais municípios os índices são inferiores a 17,50\%. É o segundo em densidade populacional com 47.686 habitantes em 2007.

As áreas protegidas no Brasil e sua categorização são regidas pela Lei 9.985/2000 que instituiu o Sistema Nacional de Unidades de Conservação da Natureza (SNUC). Estabelece os critérios e normas para a criação, a implantação e gestão das unidades de conservação. A lei entende as Unidades de Conservação como:

[...] espaço territorial e seus recursos ambientais, incluindo as águas jurisdicionais, com características naturais relevantes, legalmente instituído pelo Poder Público, com objetivos de conservação e limites definidos, sob regime especial de administração, ao qual se aplicam garantias adequadas de proteção (BRASIL, p. 5).

A variedade de categorias de UCs "atende objetivos de cunho preservacionista e socioambientalista, além de permitir certa flexibilidade $[\ldots]$ " e "[...] também seria representativa da diversidade socioambiental que um país megadiverso e de proporções continentais como o Brasil apresenta" (STRAPAZZON; MELLO, 2015, p. 173). As categorias de Unidades de Proteção Integral, que inclui os parques nacionais, têm como objetivo básico de "[...] preservar a natureza, sendo admitido apenas o uso indireto dos seus recursos naturais, com exceção dos casos previstos nesta Lei” (BRASIL, 2011, p. 9). A mesma lei, por sua vez, considera que:

O Parque Nacional tem como objetivo básico a preservação de ecossistemas naturais de grande relevância ecológica e beleza cênica, possibilitando a realização de pesquisas científicas e o desenvolvimento de atividades de educação e interpretação

DRd - Desenvolvimento Regional em debate (ISSNe 2237-9029) 
ambiental, de recreação em contato com a natureza e de turismo ecológico (BRASIL, 2011, p. 10).

A criação de áreas protegidas está associada aos impactos ambientais quantitativos e qualitativos geradas pelas diversas atividades antrópicas que se manifestam de forma contínua, crescente e complexa. Para Strapazzon e Mello (2015), da mesma forma que a questão ambiental emerge a partir da década de 1970, também é a partir deste período que a criação de áreas protegidas se prolifera pelo mundo. Assim, termos como desenvolvimento sustentável, uso sustentável e sustentabilidade tornam-se cada vez mais em voga na academia e na sociedade, incorporados inclusive na legislação ambiental e no SNUC.

Franco, Schittini e Braz (2015) no artigo História da Conservação da Natureza e das Áreas Protegidas apresentam um panorama geral da criação de áreas protegidas no mundo e no Brasil. No processo constatam que nas diversas disposições e motivações na criação e gestão de áreas protegidas insere-se a questão do desenvolvimento sustentável e o uso sustentável dos recursos naturais. No SNUC consta como um dos objetivos “[...] promover o desenvolvimento sustentável a partir dos recursos naturais" (BRASIL, 2011, p. 7), que também consta no entendimento da Reserva da Biosfera. O SNUC entende como uso sustentável a "[...] exploração do ambiente de maneira a garantir a perenidade dos recursos ambientais renováveis e dos processos ecológicos, mantendo a biodiversidade e os demais atributos ecológicos, de forma socialmente justa e economicamente viável" (BRASIL, 2011, p. 6).

O Parque Nacional da Serra do Itajaí representa um dos últimos remanescentes da Mata Atlântica, com um alto potencial de conservação da fauna e flora, e abriga inúmeras nascentes fundamentais para o fornecimento de água às populações da região (BRASIL, 2009). Ao tratar da história ambiental da Mata Atlântica, referimo-nos a um bioma diverso e extenso e mais rico em biodiversidade do que a floresta amazônica. Essa breve descrição e comparação é retratado por Warren Dean na sua obra A ferro e fogo: a história e a devastação da Mata Atlântica brasileira (GRAFT; PAULITSCH, 2012). A forma como ocorreu o processo de ocupação e uso do solo no entorno do parque, assim como no Brasil, conforme Waren Dean (1996), causaram uma drástica redução da cobertura florestal do Bioma Mata Atlântica.

Conforme Teixeira (2005, p. 53), a partir da década de 1990 o desenvolvimento sustentável é incorporado "como referência para resolver problemas e conflitos relativos à ocupação humana em unidades de conservação". Pacheco (2012) aborda a importância ambiental das UCs no Brasil nestes tempos de crise ambiental à luz da ecologia profunda, que significa adotar uma visão holística da sociedade e natureza.

No contexto da valorização da natureza, Franco, Schittini e Braz (2015, p. 262-263) argumentam que há diferentes visões e pode ser dividida basicamente em duas abordagens. Uma biocêntrica voltada "para a defesa da diversidade da vida per se, [...]. Nessa visão se enquadram os preservacionistas/conservacionistas brasileiros; [...]", e outra antropocêntrica que se preocupa "[...] principalmente, com o usufruto, ainda que racional, dos recursos naturais pelo homem e com as populações locais ou tradicionais. Nessa visão se enquadram os socioambientalistas". Os autores finalizam o artigo com o argumento de que as áreas protegidas devem considerar "[...] atitudes que valorizem os seres humanos como uma, ainda que única, dentre as milhões de outras espécies do planeta - atitudes biocêntricas e ecocêntricas".

Lester Brown introduz o conceito de sustentabilidade na década de 1980, e posteriormente Brown, Flavin e Postel (1990) definiram "sociedade sustentável como aquela 
que "satisfaz às suas necessidades sem colocar em perigo as perspectivas das gerações futuras'[...]". Em 1987, o Relatório Brundtland compreende o desenvolvimento sustentável de "[...] satisfazer às necessidades do presente sem comprometer a capacidade das gerações futuras para satisfazer às suas próprias necessidades" (CAPRA; LUISI, 2014, p. 434). Os autores também questionam o desenvolvimento sustentável, e apesar de suas definições serem "importantes exortações morais. [...], elas não nos dizem nada sobre como devemos construir uma sociedade sustentável. É por isso que tem havido muita confusão a respeito do significado de sustentabilidade, mesmo dentro do movimento ambientalista" (CAPRA; LUISI, 2014, p. 435).

Compreende-se o uso da expressão desenvolvimento sustentável, muitas vezes sem considerar a sustentabilidade ecológica. O desenvolvimento não é apenas um processo econômico, que inclui as dimensões ecológicas, sociais, culturais e éticas (CAPRA; LUISI, 2014). O Relatório Brundtland ainda "[...] reforça as necessárias relações entre economia, tecnologia, sociedade e política, como chama a atenção para a necessidade de reforçar uma nova postura ética em relação à preservação do meio ambiente, [...]" (STEINER, 2012, p. 317). Surge, assim, como uma alternativa ao cenário mundial e globalizado de degradação ambiental que visa atender as necessidades processuais dos habitantes do planeta nas suas diversas dimensões.

A colonização da região sul do Brasil, principalmente a partir do século XIX, marca profundamente a relação com a natureza desencadeando desde então grandes mudanças ambientais. Muraro (2016, p. 167) afirma que "[...] toda forma de colonização carrega em si algum sentido de dominação, muitas vezes oculta em termos como cultivar, civilizar, desenvolver e até salvar" Um dos principais interesses para a colonização da região sul do Brasil a partir de 1850 foi "[...] a possibilidade de privatização e comercialização das terras florestais" (SANTOS, 2011, p. 53). Neste contexto histórico insere-se o Vale do Itajaí com uma efetiva colonização europeia, período a ser considerado nesta pesquisa.

Sem dúvida as mudanças mais perceptíveis na forma de colonização da América aconteceram a partir da segunda metade do século XIX, com a imigração de milhares de europeus, de modo especial, italianos e alemães, que vieram promover o povoamento. Entre os novos personagens predominam os agricultores, isto é, indivíduos habilitados para dominar a natureza, arar, semear e fazer a terra produzir (MURARO, 2016, p. 167).

As fontes de pesquisa da História Ambiental são inúmeras, e Silva, Brandt e Carvalho (2016, p. 271) ressaltam a sua importância que "[...] surge respondendo aos anseios da sociedade por saber mais sobre o impacto humano na natureza ao longo do tempo, procurando alternativas ou lições no passado que possam ser úteis para os problemas ambientais contemporâneos". Também é uma área de pesquisa que está "[...] lançando novas perspectivas de análise e acrescentando novos trabalhos aos já existentes" (SILVA; BRANDT; CARVALHO, 2016, p. 272). E numa destas perspectivas “[...] é possível averiguar as limitações e vocações dos territórios obtendo informações uteis para orientar processos de desenvolvimento sustentável" (GARROTE; SANTOS, 2016, p. 01), entre as quais as UCs abrangendo as áreas do entorno e zonas de amortecimento.

Conforme Mattedi (2001) as populações deram diversos usos ao solo que geraram mudanças ambientais em diferentes graus de intensidade, imposta por suas necessidades e demandas de sobrevivência e desenvolvimento. Esse processo faz parte da história da região e 
consiste em um importante acervo para ser investigado pelo viés da abordagem teórica e metodológica da História Ambiental.

As Unidades de Conservação (UCs) são de interesse de várias áreas do conhecimento humano, inclusive da História Ambiental. As UCs por serem estoques de natureza, são a matéria prima para os estudos que focam a interação homem e o meio ambiente. Neste sentido a pesquisa aborda a natureza na História do PNSI inserindo-a como fator condicionante de influência nos processos históricos culturais.

O Sistema Nacional de Unidades de Conservação da Natureza (SNUC) exige para as de proteção integral a definição da zona de amortecimento (ZA). A Zona de Amortecimento "corresponde ao entorno imediato do PNSI, onde as atividades humanas estarão sujeitas as normas e restrições específicas" (BRASIL, 2009, p.328). Os objetivos da ZA no PNSI estão definidos no planejamento da UC:

\author{
Objetivo Geral \\ Reduzir o impacto das atividades antrópicas sobre o PNSI. \\ Objetivos Específicos \\ Promover o cumprimento das legislações ambientais vigentes para o território da Zona \\ de Amortecimento do PNSI (ZA), sobretudo em relação às áreas de preservação \\ permanente, às reservas legais e às supressões de vegetação. \\ Contribuir com o desenvolvimento humano, atual e futuro, das populações desta ZA. \\ Adequar a utilização dos recursos naturais na ZA aos parâmetros condizentes com a \\ sustentabilidade ambiental e econômica (BRASIL, 2009, p. 328).
}

Decorridos 15 anos de criação do PNSI, ainda não há estudos que demonstrem ou estabeleçam um panorama dos processos de desenvolvimento na região do parque. Tampouco se tem informações que subsidiem a gestão territorial que vise o desenvolvimento sustentável da região. Tendo esta lacuna a respeito sobre a situação do PNSI, a pesquisa tem o intuito de contribuir com o conhecimento sobre a história da sociedade humana na região, e em seguida entender, como essa sociedade se desenvolveu, e se moldou conforme os recursos e limitações do meio.

O PNSI está inserido no bioma da Mata Atlântica, predominando a Floresta Ombrófila Densa (SCHÄFFER; PROCHNOW, 2002, p. 88). De acordo com o Plano de Manejo (BRASIL, 2009), a região do PNSI caracteriza-se por exuberante paisagem, e relevo bastante acidentado e irregular com poucas áreas planas. Foi uma paisagem assim que os primeiros imigrantes encontraram ao adentrarem o Vale do Itajaí, e na região do PNSI. Essa breve caracterização natural do PNSI serve de apoio para o entendimento da interação sociedade e natureza.

O recorte de estudo abrange as comunidades situadas no entorno e na zona de amortecimento do município de Indaial (Encano Alto, Espinho e Warnow Alto), situados ao norte do PNSI. A zona de amortecimento do PNSI estabelece uma faixa de $500 \mathrm{~m}$ do entorno imediato do parque.

A proposta da pesquisa tem como abordagem teórica e metodológica a História Ambiental, para analisar de que forma ocorreram os usos exploratórios e sustentáveis na zona de amortecimento. O método de estudo consistiu em realizar uma pesquisa exploratória de caráter histórico. O levantamento histórico é uma ferramenta para conhecer os processos que constituíram e deram características simbólicas e materiais ao território, comunidades e grupos. 
As transformações sociais e ambientais na paisagem geram produtos culturais materiais e imateriais.

A compreensão dos usos da natureza no processo de colonização e desenvolvimento do território do PNSI no passado e presente baseou-se em fontes bibliográficas, e transcrições de entrevistas presentes no banco de dados do Laboratório do Grupo de Pesquisas de História Ambiental da Universidade Regional de Blumenau (FURB). As atividades de campo permitiram o reconhecimento da paisagem e a realização de entrevistas sobre a história ambiental. Para evitar constrangimento sobre determinados assuntos, como a caça e exploração madeireira, identificaram-se os entrevistados de forma numérica (e. 1, e. 2, ...). O grupo de pesquisa desenvolve pesquisas no território do PNSI desde 2004, ou seja, nos 9 municípios e nas 32 comunidades situadas na zona de amortecimento que resultaram na formação de um rico acervo de informações disponíveis para pesquisas a serem desenvolvidas no futuro.

A colonização europeia transforma significativamente a paisagem do Vale do Itajaí, e conforme o geógrafo Milton Santos (2014, p. 72-73):

A paisagem não se cria de uma só vez, mas por acréscimos, substituições; a lógica pela qual se fez um objeto no passado era a lógica de produção daquele momento. Uma paisagem é uma escrita sobre a outra, é um conjunto de objetos que tem idades diferentes, é uma herança de muitos diferentes momentos.

A paisagem consiste em um dos objetos de estudo da Geografia e da historiografia ambiental. Sobre o

[...] conceito de paisagem está um dos muitos pontos de ligação entre o trabalho de geógrafos e de historiadores. A paisagem é natural, seguramente, mas muito dela é criação e constante reconstrução feita pelos grupos sociais humanos. Ela tem, portanto, uma dimensão temporal, histórica e cultural (GERHARDT, 2012, p. 240).

A paisagem é uma construção histórica que apresenta "sinais" da ação humana. Para a identificação dos usos exploratórios da natureza no processo histórico das comunidades (antes da criação do parque), foram analisadas 08 transcrições de entrevistas, realizadas no ano de 2008, com moradores antigos das comunidades. As entrevistas possibilitam resgatar conhecimento sobre o estado da paisagem no passado, e como foi sendo alterada pelos usos da natureza, produzindo informações que se enquadram nos estudos de história com o viés da História Ambiental.

A identificação de iniciativas de usos sustentáveis nas comunidades consistiu na aplicação de questionários (sete) com todos os proprietários de empreendimentos localizados nas comunidades de estudo que dependem ou utilizam os elementos da natureza. Aplicadas no ano de 2017, o questionário direcionou-se para a obtenção de informações sobre o início e as atividades desenvolvidas nos empreendimentos, a influência da criação do PNSI no desenvolvimento dos empreendimentos, e ações e conhecimento sobre sustentabilidade por parte dos empreendedores.

Inicialmente apresenta-se o processo histórico de colonização europeia da região norte do PNSI na segunda metade do século XIX, onde se insere a formação e desenvolvimento das comunidades de Encano Alto, Espinho e Warnow do município de Indaial. A história da região está associada à formação da Colônia Blumenau em 1850. Em seguida, o estudo contempla 
especificamente os usos exploratórios e sustentáveis que ocorreram no processo histórico das comunidades antes e depois da criação do parque.

\section{PROCESSO HISTÓRICO DE COLONIZAÇÃO DO ENTORNO NO PNSI EM INDAIAL}

A região da Serra do Itajaí onde se insere o PNSI, o município de Indaial e as comunidades do estudo passaram a ser habitada inicialmente por imigrantes europeus a partir do estabelecimento da Colônia Blumenau em 1850. Ao adquirir as terras no Vale do Itajaí, Dr. Blumenau, fundador da colônia, pretendia ativar a agricultura em grande escala (DEEKE, 1995). O intento principal seria desenvolver a agricultura a partir do trabalho livre dos imigrantes. Entretanto, a "grande escala" mencionada não seria a mesma dos latifúndios do nordeste brasileiro (RENAUX, 2010), prezando, neste caso, a produção familiar.

No Vale do Itajaí, segundo Santos (2011), os lotes coloniais mediam em média 25 hectares, dispostos longitudinalmente às vias de acesso e rios, em formato retangular alongado. Essa disposição dos lotes em vales estreitos determinou que os seus fundos localizassem-se no topo dos morros.

\footnotetext{
Desta forma, as plantações, iniciadas nas várzeas avançavam pelas encostas chegando até uma pequena reserva de mata no alto das colinas. Os morros não eram totalmente desmatados, permitindo uma reserva de madeira e lenha para propriedade. Estas paisagens podem ser identificadas até hoje nas regiões rurais do vale do Itajaí (SANTOS, 2011, p. 123).
}

As comunidades localizam-se nas ramificações da Serra do Itajaí, destacando o contraste topográfico das serras e morros com poucas e estreitas áreas planas, e inúmeras nascentes contribuindo para o volume generoso dos diversos cursos de água. O relevo dificultou a prática agrícola. $\mathrm{O}$ uso do solo para fins agrícolas deu-se tanto em planícies, como nas encostas e topo de morros. Era comum encontrar árvores com troncos de diâmetro significativo como canela, peroba, cedro além de outras espécies que configuravam uma gama imensa de variedades da flora da região. A extração arbórea foi importante para os colonos na construção de suas benfeitorias (casas, ranchos, ferramentas, gamelas, móveis, entre outros), uso para lenha, e para o comércio.

[...] nas primeiras frentes de ocupação havia muito desperdício de recursos florestais, pois a procura era praticamente apenas por árvores que rendessem as melhores madeiras. Sabe-se que madeiras nobres eram usadas para fins nada "nobres" até como lenha. Aproveitava-se das árvores também só as partes mais valiosas, ficando o restante a se decompor no próprio local do abate, na mata (BRASIL, 2009, p. 44-45).

As áreas foram ocupadas para produção agrícola e pastagem. Até a década de 1980 a atividade agrícola foi mais expressiva nas comunidades, representando o seu abandono principalmente nas áreas mais íngremes das encostas. A vegetação encontrada nos morros atualmente é de capoeirinha, capoeira, capoeirão e alguns pequenos retalhos de mata secundária que não possuem mais de 30 anos de existência. 
Aproximadamente na década de 1960 o fumo começa a ser cultivado. Empresas auxiliavam na plantação, nas sementeiras, e na construção de estufas. Uma série de eventos, como as condições climáticas, diminuíram a qualidade das folhas de fumo, que motivaram o abandono do seu cultivo com o decorrer do tempo. Sobre o cultivo, afirma-se que o fumo degradou muito o solo com a utilização de agrotóxicos.

A atividade madeireira teve seu auge nas décadas de 1970 e 1980 graças à evolução tecnológica, contribuindo diretamente para o desmatamento desenfreado na região. Até meados da década de 1960 o corte das árvores e seu transporte dependiam do uso do machado e da força animal no transporte das toras. A partir de então o emprego de novas técnicas na exploração madeireira aceleraram o processo de derrubada das árvores, e facilitaram o acesso e transporte com o uso do motosserra e do trator. Na indústria madeireira o aumento da produção também se deve "à melhoria da maquinaria verificada com a aquisição de serras verticais e de serras operatrizes, além do aumento da força motriz com a utilização da energia elétrica." (EDUARDO, 1974, p. 44). As comunidades rurais são beneficiadas com a distribuição e fornecimento de energia elétrica a partir da década de 1970.

[...] um dos primeiros tratores, adquirido em 1963, dá uma pista do início da mecanização florestal na região. Antes e mesmo pouco depois dessa data era raro o uso de tratores e outros equipamentos mecanizados trabalhando em atividade madeireira. Com a mecanização, intensificada a partir da década de 1970, alguns impactos ambientais foram impressionantes. A abertura indiscriminada de estradas provocou inúmeros deslizamentos de encostas, principalmente nas áreas mais íngremes, expondo centenas de cicatrizes erosivas, algumas enormes e visíveis até hoje (BRASIL, 2009, p. 44-45).

No final do século XX os cultivos de pinus e eucaliptos tornaram-se mais comuns na paisagem:

Várias espécies de árvores exóticas e outras plantas foram também introduzidas na região e também dentro do Parque. Neste, a maior interferência foi uma plantação de Pinus sp. por volta de 1970 - 71 na região de Braço Encano, Indaial, abrangendo cerca de uma centena de hectares (BRASIL, 2009, p. 44).

Esses espaços explorados recentemente:

[...] principalmente para a extração de extensas plantações de Pinus spp. e Eucalyptus spp sem o manejo adequado, ocasionando processos erosivos acentuados. Estas atividades foram verificadas em Indaial, na estrada principal do PNSI, no Encano e Warnow, em Apiúna na comunidade do Jundiá, em Presidente Nereu na Fazenda Agrião [...] (BRASIL, 2009, p. 204-205).

A exploração madeireira é inibida na década de 1990 com a legislação ambiental ao proibir o corte e a exploração da Mata Atlântica, caso do decreto n 99.547 de 1990, e posteriormente o decreto $\mathrm{n}^{\circ} 750$ de 1993, que revoga o anterior expandindo as proibições. Os cursos de água foram fundamentais para o desenvolvimento das comunidades, desviados para o benefício de alguma família ou para a exploração madeireira (produção de energia).

No início da colonização a caça servia para incrementar e diversificar a alimentação das famílias, que muitas vezes era numerosa. A caça dificilmente ocorria durante a semana devido aos afazeres do colono na agricultura. Nos finais de semana a população da comunidade e de 
outras localidades costumavam caçar, e costumavam respeitar a época de acasalamento dos animais.

Em comunidades mais isoladas pessoas provenientes de outros lugares ainda adentram a mata para caçar. Com o decorrer do tempo, as espécies de animais começaram a diminuir, pois "[...] a prática da caça sempre foi muito intensa no vale do Itajaí, [...], que apresentava claros sinais de declínio já antes de 1950”. (BRASIL, 2009, p. 45-46). A caça e o desmatamento ameaçaram de extinção algumas espécies nativas. Animais como jacu, jacutinga, tucano, veado, paca, anta e aves em geral, sofreram um processo de escassez durante os anos em que a caça era liberada por lei. Nos anos 90, a proibição da caça não impede que a atividade seja praticada ilegalmente.

Os recursos hídricos foram fundamentais para a subsistência e desenvolvimento das comunidades. Os cursos de água eram utilizados para inúmeros afazeres, como alimentação (pesca), práticas domésticas da casa (limpeza, higiene), criação de animais, lavoura, irrigação, entre outros.

\section{USOS EXPLORATÓRIOS DA NATUREZA NAS COMUNIDADES}

No município de Indaial, o processo histórico de ocupação e uso dos recursos naturais segue a lógica da Colônia Blumenau. Os lotes eram traçados tendo frente para o rio e fundo para o topo dos morros. A ocupação do vale do Encano aconteceu em 1864 (BRASIL, 2009). Em torno de 1869 "O vale do Encano, em ambas as margens do mesmo rio já abrigava 61 famílias com 255 pessoas, [...]” (BRASIL, 2009, p. 38).

Espinho localiza-se no Vale do Encano, a montante de Encano Alto, cujo curso de água é tributário da margem direita do Rio Itajaí-açu. De forma geral, dadas às proximidades da Serra do Itajaí, as planícies de inundação são estreitas, e as encostas íngremes e elevadas favorecem a ação dos processos erosivos.

A colonização da comunidade de Encano Alto baseou-se em alemães e italianos. O solo pobre é resultante da decomposição de rochas sedimentares. Sobre os aspectos do uso do solo, primeira metade do século XX, Jamundá (1943, p. 14-15) constata no Vale do Encano que:

\footnotetext{
A cultura da cana de açúcar [...] ainda hoje é grande em relação às outras culturas. Se bem que em decadência. Porém não houvesse as impropriedades do solo, no vale do ribeirão 'Encano', reconhecidamente numa percentagem grande de terras fracas, ainda mais, castigadas pela a erosão, o mosaico e a broca, (broca da cana de açúcar DIATRAEA SACCHARALIS, FABRICIUS). Não teriam levado o lavrador ao desânimo consequentemente ao êxodo, em busca de regiões que melhormente compensassem o trabalho.
}

Os primeiros colonizadores da região praticaram a policultura, atividade que envolvia toda a família. O solo pobre requereu o seu preparo para o plantio, pois "Nós é que arrumamos a terra, mas não vinha nada, agora tem porque nós fizemos o esterco, fizemos aquela adubagem assim com folhas né, a compostagem, ali a gente arrumou tudo a terra" (e. 1, 2008). No preparo da terra empregava-se a coivara. O colono costumava vender seus produtos em Blumenau. 
Os cursos de água proporcionavam peixes que balanceavam a alimentação do colono. A pesca era uma atividade comum, e das espécies capturadas tem-se piava, jundiá, traíra entre outras. No início a água era abundante com nível mais alto dos cursos de água (e. 2, 2008). A redução significativa no seu volume contribuiu para a diminuição da quantidade de peixes. A caça fez parte da história de Encano Alto. No entanto "Caça tem ainda! O caçador! Ainda entram apesar de que é proibido, eles entram ainda, meio com medo, mas entram” (e. 1, 2008).

A exploração madeireira tem início nos primeiros anos de colonização. Para construir as casas, ranchos e ferramentas, os colonos dependiam do corte de árvores. Neste primeiro momento, porém, o corte é feito de maneira mais amena. Não se sabe ao certo o ano da instalação das primeiras serrarias na região, mas moradores revelam antes da década de 1950 . No início da exploração as toras eram tiradas a machado e "[...], naquele tempo não tinha esse negócio de trator, era só boi e cavalo. Tudo por tração de animal. Sabe como é que é, com boi, tem que começar cedo. Hoje não, é tudo mais fácil" (e. 3, 2008). Com relação às espécies retiradas:

É canela, peroba. O que mais se procurava eram canela e peroba né. Tinha o cedro, a imbaúba, tinha outras qualidades também, pindabuna, guarapari. Tudo madeira dura. Essa minha casa aqui é tudo guarapari, uma madeira dura, o cupim pode até experimentar, mas é muito dura. E o resto é tudo canela né (e. 3, 2008).

As leis de proibição do corte de árvores nativas favoreceram um plantio significativo de pinus e eucalipto. Colonos e pessoas de outros lugares que possuem propriedades na comunidade plantaram essas espécies na busca de uma renda extra. No Encano Alto, atualmente, algumas propriedades cultivam aipim, palmeira e milho. No trecho entre a referida comunidade e Espinho destaca-se o reflorestamento de Eucalipto nas encostas.

As comunidades "no vale do Warnow, alguns quilômetros acima da atual sede da cidade, a ocupação já ocorria por volta de 1869, [...].” (BRASIL, 2009, p. 36). Neste ano, ambas as margens abrigavam "31 famílias num total de 127 pessoas [...].” (BRASIL, 2009, p. 38).

Especificamente sobre "Warnou-Alto", Jamundá (1943, p. 87) apenas comenta que são terras "ainda esperando o desbravamento". Os solos também eram descritos como de baixa fertilidade, e em alguns casos, os lotes possuíam pouca quantidade de madeiras de lei. A possibilidade de terras mais baratas foi um atrativo para o colono. No Ribeirão Warnow a morfologia das planícies de inundação propicia o desenvolvimento da rizicultura.

A economia no início da colonização baseou-se na agricultura familiar. Uma das moradoras mais antigas da região afirma que "Trabalhei na Roça, toda a vida. Cortei de machado, cavei de picareta, cavei de pá, rocei mato" (e. 4, 2008).

A preparação para o cultivo do solo ocorria muitas vezes em forma de coivara, uma prática muito antiga. As principais culturas eram mandioca, milho, feijão, tomate, couve-flor, repolho, beterraba, cenoura e verduras em geral. Cultivava-se arroz em grande quantidade, e a lenha retirada era vendida ou utilizada para a construção.

Nós aqui sempre só mexemos no mato, conforme fazia a roça. Se meu pai queria fazer uma roça, ou nós mesmos queríamos fazer uma roça, ai a gente ia ver quanta madeira tinha, se tinha madeira de lei, se podia tirar para vender, para fazer um dinheirinho. Às vezes queria fazer uma cerca, ou um rancho, aproveitava tudo. Agora, hoje em dia não [...] Primeiro era assim: tu fazias uma roça, cortava uns paus de lenha, se tinha 
uns pedaços, também vendia aquilo. Tu plantavas, e aquele aipim, tu arrancavas e era vendida, aquela terra tu aproveitavas e plantava mais um ano. A gente tinha um dinheiro (e. 4, 2008).

Sobre a utilização dos produtos agrícolas, uma entrevistada (e. 4, 2008) afirma que:

A gente tinha de tudo, né. A gente plantava, cortava cana, levava nos engenhos. Aqui tinha cinco engenhos de farinha! Hoje em dia não tem mais nenhum. Três engenhos de açúcar. A gente fazia açúcar, fazia melado, fazia mousse. Como agora, no tempo das laranjas e tangerinas, tinha adoidado o mousse, e o melado por ali. Hoje em dia, não tem mais nada!

Os engenhos contribuíram para movimentar a economia da região. Alguns colonos vendiam seus produtos e, por volta da década de 1960, segundo a entrevista (e. 5, 2008): “A maioria era polonês aqui para cima, plantavam verdura. Então quando era de manhã, eram umas cinco ou seis carroças de verdura indo para a cidade. E a maioria trabalhava um pouco fora". Mudanças sucederam-se na vida do colono, inicialmente dependia da agricultura de subsistência, e posteriormente comercializa seus produtos em feiras, no centro das cidades, ou vendendo-os para empresas de conservas como a Companhia Lorenz localizada na foz do Ribeirão Encano.

Outra prática comum na comunidade era a caça. Seja na forma de esporte, ou para consumo, a caça sempre esteve presente na vida do colono. A comunidade do Warnow, que se situa a jusante do Warnow Alto, possui um dos clubes de Caça e Tiro mais antigos.

[...] a Sociedade de atiradores Warnow, que foi fundada em 13 de julho de 1873 por imigrantes alemães com o nome de Schützenverein Warnow. Foi reaberta em 1948 e teve seu nome alterado para o conhecido atualmente. Esta sociedade é a segunda mais antiga do estado de SC, que mantém a tradição do tiro ao alvo. É uma tradição que também foi trazida pelos imigrantes alemães (BRASIL, 2009, p. 89).

Um antigo morador da região afirma que "Caçavam muito antigamente, era tudo liberado né. Não tinha esse negócio. Todo mundo caçava à vontade. Andava com a espingarda nas costas pela estrada, ia de bicicleta. Caçavam muito" (e. 6, 2008). As espécies nativas mais caçadas eram os pássaros:

Era a jacutinga, na época. Hoje está em extinção, aqui acho que nem tem mais. Jacu, jacu tem ainda. Jacupema, macuco, macuco tem bastante hoje até [...]. Também o tucano né, tucanisso, tucano boi, tucano grande, tem ainda aqui. Tem a rola preta, a branca, tem o inambu chororó, o inambu verdadeiro. Tem bastante. Tem o quati, a paca também, a paca está em extinção. E tem bastante veado, esse tem bastante, quati (e. 6, 2008).

A caça "É, para comer sim. Ia lá, matava para comer e pronto" (e. 4, 2008). A maioria das famílias possuía seus animais domésticos, tais como gado, porco, galinhas, marrecos, etc. Com isto, possuíam subsídios necessários para alimentação, e a caça ficava em segundo plano. A presença de caçadores deve ter sido comum, pois algumas espécies de animais como porco do mato, jacutinga, anta, entre outros começaram a desaparecer na década de 1970.

Os cursos de água também foram indispensáveis para a alimentação do colono, sendo comum a pesca, pois "Tinha muito peixe, agora não tem mais [...]. Traíra, jundiá, piava, desses... Cará" (e. 4, 2008). O nível dos cursos de água mudou significativamente: "Mas pelo amor de Deus! Aqui, aqui, nessa água ali, nós tínhamos o rio, que passávamos por cima. Ele 
era mais estreito, mais fundo. Agora, tu passas dentro, é raso. Passa com o caminhão dentro" (e. 4, 2008). Os moradores especulam sobre a diminuição do nível das águas, entre as quais as excessivas plantações de eucalipto e o desmatamento das cabeceiras. Com o decorrer dos anos, configurou-se na região um desprendimento do uso dos cursos de água pela comunidade.

O processo de exploração madeireira na comunidade não foi diferente. A exploração ocorre no início do século XX com uma serraria que se localizava no meio da mata. Os moradores não recordam o nome da serraria, mas afirmam que foi a pioneira na exploração madeireira: "E hoje ainda está lá os pilares da serraria. Porque a madeira apodreceu, lá no meio do mato. Mas os pilares de concreto ainda estão todos lá" (e. 6, 2008). A intensificação do desmatamento ocorre por volta da década de 1960 com as serrarias, e muitas famílias passaram a trabalhar com esta atividade. Nesta época "Quando eu vim para cá, tinha 65 famílias vivendo aqui. Hoje em dia não tem 9. Vê como diminuiu né, diminuiu bastante" (e. 5, 2008). Estas famílias dependiam, então, da produção na lavoura e da indústria madeireira. Sobre as espécies de árvores exploradas, um dos entrevistados afirma:

\footnotetext{
Mas antigamente ali, eles tiravam muita madeira nobre. Madeira que era mole, não era de lei, eles até deixavam. Antigamente, sabe, eles só escolhiam o bom. Hoje em dia, eles levam tudo. Mas dava muita canela, peroba, itaúba. Madeira de lei, né. Jacarandá, itaúba, até tarumom tinha ali, mas era pouco né. O que mais dava era peroba e canela (e. 6, 2008).
}

Um dos entrevistados que trabalhou numa serraria afirma que se cortava muita árvore nativa:

\begin{abstract}
Aqui antigamente vinham mais ou menos uns 10, 11 metros cúbicos de madeira nativa né, de toras. E depois a gente serrava. E aí serrava e saía 5, 4 metros cúbicos, depende o tamanho da casa. Isso vinha em tronco para cá [...] não tenho mais a noção de quanto dá isso. Olha, eu serrava mais ou menos umas 10, 12 toras por dia no começo. Era daquele tipo de serralharia 'zip zap', era com roda d'água. Depois de uns 5 ou 6 anos é que foi colocado a fita (e. 5, 2008).
\end{abstract}

No ribeirão Warnow, nos vales mais abertos destaca-se o cultivo de arroz. Palmeiras e outras culturas são menos expressivas, e algumas propriedades cultivam produtos orgânicos. A montante, Warnow Alto, o relevo mais íngreme diminui consideravelmente a área cultivável. De modo geral, a vegetação primária foi suprimida, e nas encostas íngremes encontra-se, atualmente, o desenvolvimento de uma mata secundária.

\title{
USOS SUSTENTÁVEIS DA NATUREZA NAS COMUNIDADES
}

O desenvolvimento das comunidades antes da criação de leis ambientais mais rígidas no início da década de 1990, e do PNSI em 2004, estavam atrelados ao maior uso do solo pela agricultura e a exploração da Mata Atlântica. Diante das restrições no uso dos recursos naturais, o Plano de Manejo do PNSI ao considerar o potencial da zona de amortecimento e entorno aponta as seguintes alternativas de desenvolvimento econômico sustentável (BRASIL, 2009, p. 86): 
Projetos relacionados à substituição de espécies exóticas de peixes por espécies nativas;

Implantação de sistemas agroflorestais, agricultura orgânica e agroecologia; Projetos relacionados ao incremento da atividade turística na região: apoio técnico, parcerias com o terceiro setor, realização de cursos para formação de guias locais, possibilidade de operadoras locais poderem explorar o turismo e comercialização de produtos produzidos na região.

Em seguida o Plano de Manejo sugere estratégias para a implantação das potencialidades (BRASIL, 2009, p. 86):

[...] estímulo à pluriatividade nas famílias, ou seja, a promoção de diferentes atividades simultâneas nas propriedades e o fortalecimento através de articulação política nas comunidades, seja para formação e/ou implementação de cooperativas na região. Tais atividades são fundamentais para que as comunidades permaneçam nas áreas rurais e se beneficiem da proximidade com a UC.

Sobre o planejamento do PNSI e da zona de amortecimento "A metodologia de planejamento para sua elaboração foi participativa e incluiu diversos momentos de integração com a comunidade do entorno, a sociedade civil e o Conselho Consultivo" (BRASIL, 2009, p. 242). O planejamento estabelece Áreas Estratégicas Internas que são “[...] relevantes para o manejo e o alcance dos objetivos do PNSI e foram definidas, especialmente, por apresentarem condições ecológicas singulares e demandarem atividades específicas [...]" (BRASIL, 2009, p. 394).

A área estratégica interna no Vale do Encano sugere uma série de serviços e infraestruturas como "Centro de Visitantes Alto Encano; Guarita; alojamentos para funcionários, monitores, convidados e pesquisadores; área de piquenique; lanchonete; lojas; um trecho da estrada principal do PNSI; as Trilhas [...]" (BRASIL, 2009, p.418), que permitiriam apreciar a beleza cênica da paisagem. Assim, poderiam ser desenvolvidas inúmeras atividades de turismo, lazer, pesquisa entre outras.

Para Warnow Alto o planejamento sugere trilhas, com atividades de lazer, sensibilização ambiental, pesquisa, entre outras. De modo geral, o planejamento visa a recuperação e preservação, manejo das espécies, promover a relação sociedade e natureza através de visitas, estabelecimento de trilhas sinalizadas, e instalações necessárias para o apoio das atividades. Entretanto, estes planejamentos citados para as comunidades até o momento não estão sendo colocados em prática.

As comunidades localizadas no entorno do município de Indaial apresentam potencial para o desenvolvimento sustentável, por se tratar de uma região rica em recursos hídricos. Os cursos de água recebem muitos banhistas no verão, mas realizada de forma desordenada. Também possui potencial para tornar-se polo para os recantos. Entretanto, as iniciativas ainda são tímidas para fomentar o ecoturismo conforme o levantamento dos empreendimentos.

No entorno do PNSI, nas comunidades analisadas há empreendimentos familiares de baixo investimento que aproveitam os cursos de água e outros elementos naturais como um potencial para o turismo e lazer. As propriedades que usam os recursos naturais da região, principalmente os ribeirões, associam o consumo e lazer de fim de semana de muitas famílias durante as temporadas de verão. 
Ao todo foram levantados 07 empreendimentos nas comunidades de Indaial no ano de 2017. Em Encano atividade de bar e lanchonete (1); Alto Encano bar e camping (1); Espinho pousada (1); Warnow produção de orgânicos (1); em Warnow Alto uma propriedade com criação de equinos e uma microempresa de pallets que utiliza eucalipto, e serraria (01) que beneficia eucaliptos e pinos.

Os dois primeiros empreendimentos apresentam infraestrutura para aproveitar o uso dos cursos de água no verão. Apresentam potenciais de atividade econômica na região condizente com os objetivos da Zona de Amortecimento previstas no Plano de Manejo. No Warnow a iniciativa na produção de orgânicos é de um grupo de 4 a 5 proprietários (pequenos produtores) que defendem a isenção do uso de químicos na produção, e também está alinhada com as alternativas de desenvolvimento econômico sustentável propostas para as propriedades rurais do entorno do Parque. Para fortalecer a atividade, um dos produtores afirma que poderia ser melhorada a relação entre as entidades de conhecimento técnico científico com a prática dos agricultores.

Os empreendimentos em sua maioria surgiram antes da criação do PNSI, exceto a pousada localizada em Espinho que tem menos de 10 anos de atividade, e dos pequenos produtores de orgânicos. Mas a iniciativa dos empreendimentos, conforme proprietários, não tiveram influência e relação com o parque. Enfim, não se constata nas comunidades iniciativas sustentáveis estimuladas pela criação do parque. A maioria dos proprietários entrevistados não tem opinião formada acerca do conceito de desenvolvimento sustentável, e de sua aplicabilidade. Contudo, evidenciam a importância da preservação do meio ambiente para desenvolverem suas atividades. Em relação à legislação ambiental, todos os proprietários afirmam que, em suas comunidades, os empreendimentos preocupam-se com o meio ambiente, adequando-se às normas legais.

Todos os proprietários sabem da existência do PNSI e apoiam o ideal preservacionista da instituição. Contudo, existem críticas sobre a forma como foi instituído, pela lentidão de indenizações de algumas propriedades, e de uma melhor vigilância para inibir a ação de caçadores e extratores de palmito. O PNSI contribuiu no sentido de melhorar a preservação da região e dos recursos hídricos, aumentando o fluxo de banhistas e visitantes. Os beneficiados são o camping e bar e lanchonete localizado em Encano, graças aos seus atrativos, que apresentam infraestrutura para banhistas. No Warnow:

[...] destaca-se a arquitetura enxaimel, presente em várias propriedades, inclusive na Igreja Enxaimel localizada no bairro [...]. Trazida pelos imigrantes alemães, esta técnica se transformou numa das expressões mais características da cultura desse povo. Atualmente, não foi verificado o desenvolvimento de atividades turísticas expressivas no local, mas esta peculiaridade evidenciada demonstra um bom potencial para a região (BRASIL, 2009, p. 89).

Conforme os entrevistados, nos últimos 5 anos as comunidades apresentam um aumento gradativo de turistas representados por grupos de ciclistas e trilheiros. Nas comunidades existem trilhas que adentram na área do parque que favorece a atividade turística, mas ao mesmo tempo facilita a incursão de palmiteiros e caçadores. No Vale do Encano, próximo e dentro do parque, ainda encontram-se cultivos de pinos e eucaliptos. No Vale do Warnow existem propriedades como sítios de temporada, e algumas propriedades rurais com moradores fixos que cultivam em grande escala arroz, milho, aipim e frutíferas. Alguns proprietários de 
sítios limítrofes da ZA do PNSI possuem interesse em montar pousadas, ou investir em estabelecimentos, que valorizem os recursos hídricos e trilhas que adentram no parque.

Em suma, identifica-se nas comunidades localizadas na zona de amortecimento e entorno do PNSI no município de Indaial, a partir da colonização europeia no século XIX, três períodos de usos exploratórios e sustentáveis da natureza. O primeiro (década de 1860 até a década de 1950) inicia um processo de modificação da paisagem, principalmente pela exploração florestal, pastagem, agricultura e caça. Neste período os usos dos recursos naturais dependiam mais da força humana e animal. O europeu e seus descendentes apreenderam com a cultura local a se adaptar e a se desenvolver no ambiente da Floresta Atlântica. A interação homem e natureza representou para a cultura europeia um desafio na exploração da Mata Atlântica. Essa experiência determinou um novo ritmo de uso do ambiente, e logo as matas são substituídas pelas pastagens e plantações gerando o lugar das comunidades. Entrelaçam-se as culturas do caboclo brasileiro do Vale do Itajaí com a cultura do povo alemão e italiano, nos moldes apresentados por Ribeiro (2008). O autor afirma que no sul do Brasil houve uma integração dos imigrantes alemães ao modo de vida brasileira.

O segundo período (década de 1960 até década de 1980) marca o início da adoção de novas tecnologias na agricultura propiciadas pela revolução verde e na exploração da Mata Atlântica com a introdução do trator, motosserra, e modernização dos equipamentos utilizados nas serrarias. É o período de clímax dos usos exploratórios, e a paisagem dos vales do Encano e Warnow ficam quase descobertos da floresta. O modo de vida do colono desenvolvido no a partir do primeiro período, de exploração de madeiras de lei, da coivara, produção de carvão, retirada do palmito, caça e pesca altera-se conforme as necessidades do mercado regional, e da evolução urbana. A partir da década de 1960 acontece um processo de esvaziamento demográfico das regiões, principalmente dos mais jovens que migram aos centros urbanos para empregaram-se nas fábricas. Ocorre a introdução em grande escala dos cultivos de eucaliptos e pinus. A introdução do cultivo do fumo representou uma nova alternativa de renda. $\mathrm{O}$ desenvolvimento da atividade dependeu do uso de lenha obtido da Mata Atlântica, que contribuiu para a retração da cobertura florestal. Até a década de 1980 a Floresta Atlântica apresenta uma história muito próxima da narrada por Dean (1996).

No final deste período há uma nova configuração espacial nas comunidades com parcelamento dos lotes, criação de moradias de temporada, como sítios e chácaras, que reduziram os usos exploratórios e uma menor degradação da floresta. A partir da década de 1970, intensificando-se em 1990, movimentos socioambientais contribuem com a crítica sobre os usos exploratórios, e defendem o desenvolvimento sustentável. A criação de uma área de proteção natural em 1988 (Parque Ecológico Artex, abrangendo os municípios de Blumenau, Guabiruba e Indaial) tornou-se embrião para a criação do PNSI no terceiro período.

O terceiro período (1990 aos dias atuais) rompe bruscamente o período anterior devido às leis ambientais (decretos $n^{\circ} 99.547$ de 1990, e posteriormente o decreto $n^{\circ} 750$ de 1993) que coíbem a exploração florestal da mata nativa. Consequentemente mudam as práticas das atividades socioeconômicas nas comunidades, e inúmeras serrarias interrompem as suas atividades na região. A atividade agrícola também retrai significativamente, e aumenta a cobertura vegetal nas áreas abandonadas, favorecendo a sucessão florestal e novos modelos de atividades econômicas introduzem um novo desenvolvimento nas comunidades. 
A partir do terceiro período, a proteção da biodiversidade e dos recursos hídricos na região favorece a conservação dos atrativos naturais e propiciam o desenvolvimento de empreendimentos e atividades de lazer. A criação do PNSI em 2004 estabelece um novo processo de uso do ambiente nas comunidades, que atualmente vive um processo de adaptação e transição de desenvolvimento. A partir do estabelecimento do Plano de Manejo em 2009, a região passa a ser palco de iniciativas de usos do ambiente mais sustentáveis do que se apresentou nos períodos anteriores. É de responsabilidade do município, administração da UC e sociedade do entorno desenvolver iniciativas que colaborem com o desenvolvimento sustentável, substituindo as práticas de usos exploratórios por usos sustentáveis.

Nas comunidades encontra-se um processo embrionário do desenvolvimento sustentável. A falta de políticas ou programas que incentive novas formas de desenvolvimento é reflexo do comprometimento do poder público e privado. A presença do PNSI pouco contribuiu para a formação de novas atividades econômicas na região, como pousadas, recantos, ou estabelecimentos que valorizem a natureza local e promovam a sustentabilidade ambiental. É indispensável incentivar na região práticas de usos sustentáveis como estabelece o Plano de Manejo do PNSI.

\section{CONSIDERAÇÕES FINAIS}

Nas comunidades estudadas há uma História de interação entre sociedade e natureza de usos exploratórios e sustentáveis dos recursos naturais. Identificaram-se três períodos que distinguem o ritmo de uso dos recursos naturais e mudanças na paisagem. Nos dois primeiros períodos, antes da criação do PNSI, o modelo de desenvolvimento das comunidades estava atrelado e dependente exclusivamente da exploração da natureza.

O desenvolvimento no primeiro período teve características endógenas. A evolução urbana e demográfica do município de Indaial e região aumentaram as demandas de produtos da floresta, como madeira, água; e produtos da agricultura e pecuária, que ampliaram os usos exploratórios nas comunidades para atender as demandas dos mercados locais. Isso fica marcante na segunda fase, pois o desenvolvimento endógeno das comunidades depende de fatores exógenos do desenvolvimento regional.

Nos anos de 1970-80 a superexploração do ambiente esgota uma série de recursos, como a madeira de lei; a fauna reduz drasticamente e os recursos hídricos são muito afetados. Essas características configuram o antigo modelo de desenvolvimento pautado na exploração.

No terceiro período são os fatores exógenos que configuram o desenvolvimento local, pois leis ambientais e a criação do PNSI restringem a exploração da Mata Atlântica e o uso dos recursos naturais. A criação do PNSI impõe no espaço novas regras de uso do solo, que afeta drasticamente o modelo de vida pautado na exploração, e passa a direcionar usos sustentáveis da natureza. O PNSI através do Plano de Manejo estabelece estratégias para o desenvolvimento sustentável da região, mas constata-se a falta de participação do poder público e entidades privadas. Estes não conseguiram incentivar ou promover nas comunidades novos modelos de atividades econômicas, como recantos, pousadas e propriedades rurais voltados para a sustentabilidade ambiental através da agroecologia. 
Contudo, a presença do PNSI favorece a natureza e contribui para mudar a paisagem das comunidades, em que predomina a floresta secundária, e estimula lentamente o turismo. Consequentemente tem despertado em alguns proprietários ideias de criação de pousadas ou espaços que aproveitem para o turismo e lazer os recursos naturais. Constata-se nas comunidades um processo de transição de um modelo de desenvolvimento de usos exploratórios para usos mais sustentáveis do ambiente do entorno e zona de amortecimento do PNSI.

\section{REFERÊNCIAS}

BRASIL. Plano de Manejo Parque Nacional da Serra do Itajaí. Brasília: ICMBIO, 2009.

BRASIL. MMA. SNUC (Sistema Nacional de Unidades de Conservação da Natureza). Lei $\mathbf{n}^{\mathbf{0}}$ 9.985, de 18 de julho de 2000; Decreto $n^{\circ}$ 4.340, de 22 de agosto de 2002; Decreto $n^{\circ}$ 5.746, de 5 de abril de 2006. Plano Estratégico Nacional de Áreas Protegidas: Decreto $\mathrm{n}^{\circ}$ 5.758, de 13 de abril de 2006. Ministério do Meio Ambiente. Brasília: MMA/SBF, 2011.

CAPRA, F.; LUISI, P. L. A visão sistêmica da vida: uma concepção unificada e suas implicações filosóficas, políticas, sociais e econômicas. São Paulo: Cultrix, 2014.

DEAN, W. A ferro e fogo: a história e a devastação da mata atlântica brasileira. São Paulo: Companhia das Letras, 1996.

EDUARDO, R. P. A madeira em Santa Catarina: 1930-1974. 1974. 180 f. Dissertação (Mestrado em História do Brasil) - Setor de Ciências humanas, Letras e Artes, Universidade Federal do Paraná, Curitiba, 1974.

FRANCO, J. L. de A.; SCHITTINI, G. de M.; BRAZ, V. da S. História da conservação da natureza e das áreas protegidas: panorama geral. Historiæ, Rio Grande, v. 6, n. 2, p. 233-270, 2015.

GARROTE, M. S.; SANTOS, G. F. dos. A contribuição da história ambiental para o desenvolvimento sustentável. In: SEMINÁRIO DE DESENVOLVIMENTO REGIONAL, Anais... Blumenau: FURB, 2016.

GERHARDT, M. Os caboclos e a história da paisagem. In: ZARTH, P. A. (Org.). História do campesinato na Fronteira Sul. Porto Alegre: Letra \& Vida: Chapecó: Universidade Federal da Fronteira Sul, 2012. p. 240-255.

GRAFT, L; PAULITSCH, N. S. O legado da obra A Ferro e Fogo: a história e a devastação da mata atlântica brasileira. In: BUTZKE, A.; PONTALTI, S. (Org.). Os recursos naturais e o homem: o direito ao meio ambiente ecologicamente equilibrado frente à responsabilidade solidária. Caxias do Sul, RS: Educs, 2012. p. 365-379.

JAMUNDÁ, T.C. Indaial: município do Vale do Itajaí-açú. Indaial: Arquivo Histórico Municipal Theobaldo Costa Jamundá, 1943. 
MATTEDI, M. A. Notas sobre as visões de natureza em Blumenau: mais um capítulo da trágica história do sucesso humano. Revista de estudos ambientais, Blumenau, v. 3, n. 1, jan./abr., p. 29-39, 2001.

MURARO, V. F. Sobre fronteiras e colonização. In: RADIN, J. C.; VALENTINI, D. J. (Org.). História da Fronteira Sul. Chapecó: Ed. UFFS, 2016. p. 167-189.

PACHECO, C. S. Unidades de Conservação à luz da ecologia profunda. In: In: BUTZKE, A.; PONTALTI, S. (Org.). Os recursos naturais e o homem: o direito ao meio ambiente ecologicamente equilibrado frente à responsabilidade solidária. Caxias do Sul, RS: Educs, 2012. p. 227-241.

RIBEIRO, D. O povo brasileiro: a formação e o sentido do Brasil. São Paulo: Companhia de Bolso, 2008.

SILVA, C. M.; BRANDT, M.; CARVALHO, M. M. X. Uma história ambiental da Fronteira Sul: campos, florestas e agroecossistemas. In: RADIN, J. C.; VALENTINI, D. J. (Org.). História da Fronteira Sul. Chapecó: Ed. UFFS, 2016. p. 271-297.

STEINER, V. L. Tutela ambiental e jurídica da Reserva de Desenvolvimento Sustentável. In: In: BUTZKE, A.; PONTALTI, S. (Org.). Os recursos naturais e o homem: o direito ao meio ambiente ecologicamente equilibrado frente à responsabilidade solidária. Caxias do Sul, RS: Educs, 2012. p. 309-330.

STRAPAZZON, M. C.; MELLO, N. A. Um convite à reflexão sobre a categoria de unidade de conservação refúgio de vida silvestre. Ambiente \& Sociedade, São Paulo, v. 18, n. 4, p. 161-178, out.-dez. 2015.

TEIXEIRA, C. O desenvolvimento sustentável em unidades de conservação: a "naturalização" do social. Revista Brasileira de Ciências Sociais, São Paulo, v. 20, n. 59, p. 51-66, 2005. 